
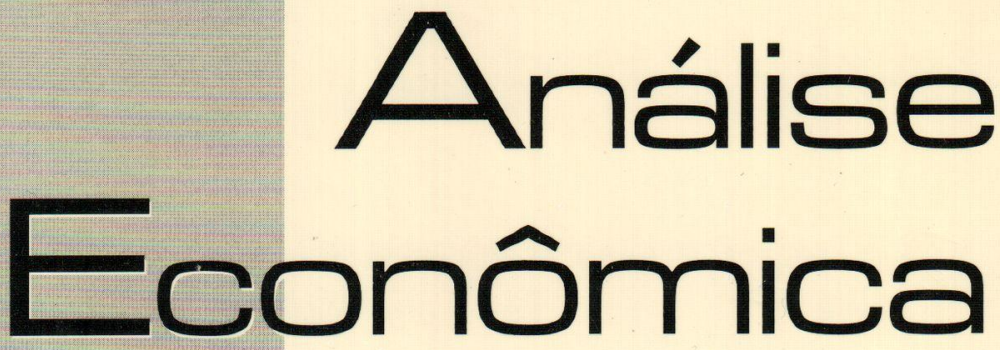

FATOS ESTHLIZADOS E CORRELAÇÁ O NO SETOR BANCÁRIO BRASILEIRO

IGOR AlexandRe C. DE MORAES

Política Monetária, Expectativas e Derivativos: uma ANALISE DO BRASIL PERIODO 1995-98

ROGERIO SOBREIRA

O FEDERAL RESERVE EM DOIS MOMENTOS DISTINTOS: ATUAÇÃO NA GRANDE DEPRESSÃO E NO FINAL DOS ANOS 1990

ROBSON RODRIGUES PEREIRA

BASHLÉIA 2 E ECONOMIAS EMERGENTES: UMA ABORDAGEM MÉDIA-VARIÁNCIA

otaViano Canuto e ANTÓ Nio josé MEIRELLES

VULNERABILIDADES EXTERNAS E INTERNAS DAS ECONOMIAS EMERGENTES E PADRÁ O DE CONTÁ GIO. A EXPERIÉnCIA DA DECADA DE 90

MiLTON PEREIRA OE ASSIS

ENDIVIDAMENTO PÚ BLICO E IMPACTO SOBRE FLUXOS DE CAPITAIS, RISCO-PAIS DIFERENCIAL DE JUROS NO BRASIL (1995-2002): MODELO VAR E TESTES DE CAUSALIDADE FLÁ VIO VILELA VIEIRA

METAS SOCIAIS DE PROCRAMAS DE MICROCRÉ DITO FINANCEIRAMENTE VIÁ VEIS

FERNANDO BATISTA PEREIRA E MARCO CROCCO

Estrutura Produtiva e Performance econó mica das ECONOMIAS ESTAdUAIS BRAsILIRAS NA DECADA DE NOVENTA ADELAR FOCHEZATTO

HISTORIA ECONO MICA Y TEORIA ECONO MICA: ENCUENTROS Y DESENCUENTROS

Gabriel PorciLe

EM BUSCA DA NOÇÃ O EVOLUCIONÁRIA (NEO-

SHUMPETERIANA) DO AUTO-INTERESSE DOS AGENTES: UMA CONTRIBUIÇAO A PARTIR DA LITERATURA SOBRE COOPERAÇÁO INTERFIRMAS

ROBSON ANTONIO GRASS

PRINCiPIOS E APULAÇó Es de REGRESSÁo Local ADALMIR MARQUETTI E LORI VIAL

globalizaçáo, Crescimento e pobreza, a Visäo do BANCO MUNDIAL SOBRE OS EFETTOS DA GLOBALIZAÇÁO NALI DE JESUS DE SOUZA

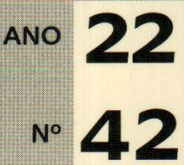




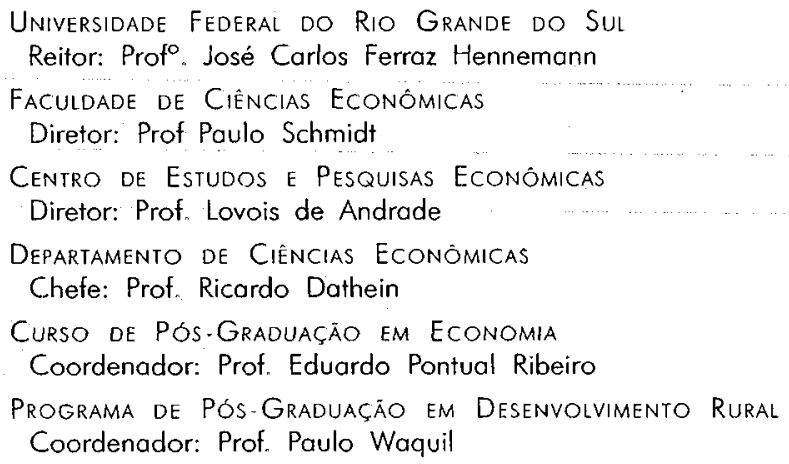

CONSELHO EDITORIAL:

André M. Cunha (UFRGS), Carlos G. A. Mieliz Netto (UFRGS), Carlos H. Hom (UFRGS), Eduardo $A_{n}$ Maldonado Filho (UFRGS), Eduardo P. Ribeiro (UFRGS), Eleutério F. S. Prado (USP), Eugênio Lagemann (UFRGS), Fernando Cardim de Carvalho (UFRJ), Fernando Ferrari Filho (UFRGS), Fernando de Holanda Barbosa (FGV/RJ), Flávio Vasconcellos Comim (UFRGS), Flávio A. Ziegelman (UFRGS), Gentil Corazza (UFRGS), Giácomo Balbinotto Netto (UFRGS), Gilberto de O. Kloeckner(UFRGS), Gustavo Franco (PUC/RJ), Hélio Henkin (UFRGS), Jairo L. Procianoy (UFRGS), Jan A. Kregel (UNCTAD), João Rogério Sanson (UFSC), Joaquim Pinto de Andrade (UnB), Jorge Paulo Araújo (UFRGS), José R. Iglesias (UFRGS), Júlio C. Oliveira (UFRGS), Luis P. Nogueról (UFGS), Luiz E. Faria (UFRGS), Marcelo S. Portugal (UFRGS), Maria Alice Lahorgue (UFRGS), Octávio A. C. Conceição (UFRGS), Orlando Martinelli (UFRGS), Paul Davidson (University of Tennessee), Paulo D. Waquil (UFRGS), Paulo Schmidt (UFRGS), Pedro C. D. Fonseca (UFRGS), Philip Arestis (University of Cambridge), Ricardo Dathein (UFRGS), Roberto C. de Moraes (UFRGS), Ronald Otto Hillbrecht (UFRGS), Sérgio M. M. Monteiro (UFRGS), Sabino da Silvo Porto Jr. (UFRGS), Stefano Florissi (UFRGS) e Werner Baer (University of Illinois at Urbana-Champaign).

COMISSÃO EDITORIAL:

Eduardo Augusto Maldonado Filho, Fernando Ferrari Filho, Gentil Corazza, Marcelo Savino Portugal, Paulo Dabdab Waquil e Roberto Camps Moraes.

EDITOR: Prof. Fernando Ferrari Filho

Egitor Adunto: Prof Gentil Corazza

Secretário: Paulo Roberto Eckent

REVISÁO DE TEXTOS: Vanete Ricacheski

Eottoraçáo Eletrónca: Nucleo de criação e editoraçáo Gráfica UFrgs: leonardo ponso Fundador: Prof. Antônio Carlos Santos Rosa

Os materiais publicados na revista Análise Econômica são da exclusiva responsabilidade dos autores. É permitida a reprodução total ou parcial dos trabalhos, desde que seja citada a fonte. Aceita-se permuta com revistas congêneres. Aceitam-se, também, livros para divulgação, elaboração de resenhas e recensōes Toda correspondência, material para publicação (vide normas na terceira capa), assinaturas e permutas devem ser dirigidos ao seguinte destinatário:

PROF. FERNANDO FERRAR! FILHO

Revista Análise Econômica - Av. João Pessoa, 52 CEP 90040-000 PORTO ALEGRE - RS, BRASIL Telefones: (051) 316-3513 - Fax: (051) 316-3990

Análise Econömíca E-mail: rae@ufrgs.br

Ano 22, $n^{\circ} 42$, morço, 2004 - Porto Alegre

Faculdade de Ciências Econômicas, UFRGS, 2004

Periodicidade semestral, março e setembro.

Tiragem: 500 exemplares

1. Teoria Econômica - Desenvolvimento Regional -

Economia Agrícola - Pesquisa Teórica e Aplicada.

Periódicos. 1. Brasil.

Faculdade de Ciências Econômicas,

Universidade Federal do Rio Grande do Sul. 


\section{Fatos estilizados e correlação no setor bancário brasileiro}

Igor Alexandre C. de Morais ${ }^{1}$

Resumo: Este artigo usa vários modelos univariados para determinar os fatos estilizados em finanças para quatro séries de ações de bancos brasileiros entre 02/08/1994 a 02/10/2000, três privados e um público. Na maior parte das séries, não há evidência de distribuição normal, há a presença de assimetria, aglomeração de volatilidade e alta persistência. Os resultados mostram que os retornos médios do banco estatal são menores do que os verificados para os três bancos privados. Através do uso do modelo de correlação condicional constante de Bollerslev (1990), verificou-se um crescimento na correlação entre as volatilidades das instituições financeiras após a implementação do programa de privatização dos bancos estatais, com destaque para o aumento da correlação entre o banco estatal e os privados.

Palavras-chave: GARCH, correlação condicional constante, volatilidade.

Abstract: This paper use different univariate models to perform the stilized facts in finance in four series from brazilian stock market between August/02/ 1994 to October/02/2000, three private and one public. The results show that most of series have non normal distribution, leverage effect, volatility clustering and high persistence in volatility. Is noted that the state bank has low medium return by comparison to others private banks. Using the constant conditional correlation model of Bollerslev(1990), the growth in correlation between the volatility from financial system, after the implementation of program of privatization of states banks is evident, in special between the state and private banks.

Keywords: GARCH, constant conditional correlation, volatility.

JEL Classification: C13 Estimation, C32 Time Series Models, G1 General Financial Markets.

\section{Introdução}

A estabilidade de preços conseguida com o Plano Real modificou sobremaneira a relação entre os agentes econômicos, em especial as transaçōes dentro do Sistema Financeiro Nacional. De imediato o que se verificou foi uma redução da receita infla-

${ }^{1}$ Doutor em economia e economista FIERGS. 
cionária dos bancos, o float, e estes se viram obrigados a buscarem fontes de receitas alternativas como, por exemplo, a cobrança por diversos serviços oferecidos a clientes e que antes eram gratuitos.

Esta nova arquitetura macroeconômica acabou resultando em agravamento dos problemas de liquidez e solvência de vários bancos, em especial aqueles de menor porte, colocando em risco o plano de estabilização econômica. ${ }^{2}$ Assim é que em 1995 foi instituído o programa de estímulo à reestruturação e ao fortalecimento do Sistema Financeiro Nacional - PROER - que tinha como objetivo preservar a estabilidade do sistema de pagamentos e penalizar as más políticas bancárias.

Dentro deste arcabouço iniciou-se um processo de fusões e aquisições, com o aumento da participação de bancos estrangeiros, que modificou sobremaneira a estrutura bancária do país. Como complemento desta política, o governo brasileiro implementou em 1996 um programa de incentivo à redução da participação do setor público estadual na atividade bancária, o PROES. Com isso, o número de bancos estatais passou de $35 \mathrm{em}$ 1996 para 12 ao final de 2002, ver Maia (2003) e Goldfajn et al. (2002).

Após esta reestruturação, o sistema bancário brasileiro tornou-se mais competitivo, transparente e eficiente, o que reduziu os riscos de uma crise sistêmica. Apesar disto, um dos maiores bancos do país, o Banco do Brasil, ainda tem como maior controlador individual o governo federal. Porém, é importante salientar que os critérios de monitoramento das instituições financeiras no Brasil feito pelo Banco Central aperfeiçoaram-se nestes últimos anos, e os bancos públicos não ficaram à margem deste processo. ${ }^{3}$

Sendo assim, é natural imaginar que, após a implementação destes programas de reestruturação do sistema bancário, o risco oferecido por um banco público ao seu acionista apresentasse uma redução comparativamente à situação anterior, quando tanto as regras existentes para as instituições financeiras públicas quan-

2 Entre 1994 e 1995, o Banco Central do Brasil liquidou ou interveio em 28 bancos.

3 Em 2001 foi criado o programa de fortalecimento das instituições financeiras federais, PROEF e, como contrapartida, os bancos públicos envolvidos neste programa ficaram sujeitos a regras mais rígidas do que as exigidas pelo acordo da Basiléia. De acordo com Goldfajn et al. (2002), o custo fiscal destes três programas foi da ordem de 8 a $9 \%$ do PIB. 
to a estrutura de mercado eram diferentes. Além disso, uma hipótese a ser comprovada é se estes programas conseguiram fazer com que o investidor passasse a precificar as ações do maior banco público, o Banco do Brasil, da mesma forma que são precificadas as ações de bancos do setor privado, ou seja, comprovar se a correlação entre a volatilidade daquele está mais próxima destes.

Uma ferramenta econométrica útil para verificar estas hipóteses são os modelos univariados e multivariados da família $\mathrm{ARCH}$, uma vez que estes permitem analisar o comportamento da volatilidade de qualquer série de dados ao longo do tempo. Além disso, vale ressaltar, a estrutura $\mathrm{ARCH}$ permite a modelagem da resposta dos agentes econômicos às incertezas da economia a partir da medida de variância.

$O$ artigo seminal nesta literatura é o de Engle (1982), que propôs estimar o segundo momento de forma conjunta com o primeiro em uma estrutura auto-regressiva. Posteriormente, Bollerslev (1986) estendeu o modelo ARCH incorporando, na equação do segundo momento, a variância condicional defasada. Este modelo é conhecido na literatura como GARCH. A partir de então, dada a flexibilidade e a quantidade de informações que estes mo* delos podem fornecer sobre a série que está sendo estudada, diversas variantes surgiram. ${ }^{4}$

Em relação à sua aplicação a séries financeiras brasileiras, vários autores utilizaram estas formulações para verificar algumas características dos ativos, como a aglomeração de volatilidade, a assimetria e a persistência. Em relação a índices de mercado, a aplicação dos modelos da família GARCH univariados foi feita por Bustamante et al. (1995), Morais et al. (1999), Correa et al. (1998), Alves et al. (1998) e Almeida et al. (1999).

Para uma aplicação a ações de empresas do mercado brasileiro, ver Herência et al. (1998), Barcinski et al. (1997), Duarte et al. (1996) e Issler (1999). Uma nova classe de modelos, os SWGARCH, foi utilizada por Moraes et al. (2002) para evidenciar uma mudança de regime ocorrida em ações de empresas do setor siderúrgico e bancário após a entrada em funcionamento na bolsa brasileira do novo mercado.

4 Para uma discussāo sobre a abordagem dos modelos da familia GARCH em finanças, ver Bollerslev et al. (1992). 
Em comum nestes artigos o fato destas séries financeiras revelarem uma distribuição não-gaussiana, possuindo, assim, tanto assimetria quanto curtose, o que implica a existência de caudas mais pesadas. Esta característica foi evidenciada em Delgado (1994), Ziegelmann et al. (1997) e Morais et al. (1999). Vale ressaltar que encontrar estas evidências para retornos de ações e índices é importante não apenas para uma melhor formulação teórica de modelos que descrevem o comportamento destas séries e a aplicação destes em seleção de portfólios e precificação de ativos, mas também para a avaliação dos riscos de um investimento.

Além disso, as séries financeiras, em sua grande maioria, possuem autocorrelação em seu quadrado, o que caracteriza a existência de uma dependência não-linear, ver He et al. (1997). Sendo assim, é de se esperar que a abordagem padrão de heteroscedasticidade, no qual introduz uma variável exógena ao modelo, não é a ideal para caracterizar a modelagem da variância condicional. Ou seja, mesmo que a variância não condicional (longo-prazo) seja constante com a série apresentando estacionariedade, pode ocorrer que, em determinados períodos de tempo exista uma dependência da variância em $t$ para com a variância em $t$-1. Esta característica revela a existência de heteroscedasticidade condicional.

Portanto, este artigo tem dois objetivos. Em primeiro lugar aplicar diferentes modelagens univariadas e testes econométricos existentes na literatura para evidenciar algumas características que são observadas em séries financeiras: a persistência, a assimetria a choques e a aglomeração de volatilidade. São utilizados retornos diários de ações das quatro maiores empresas do setor bancário negociadas no mercado de bolsa brasileiro no período de 2 de agosto de 1994 a 2 de outubro de 2000, Banco do Brasil, Bradesco, Itaú e Unibanco:

O segundo objetivo deste trabalho é evidenciar se as ações do sistema financeiro apresentaram mudança na correlação a partir do PROER e PROES, em especial após a privatização do Banerj em 26 de junho de 1997. Para tanto, é utilizado o modelo multivariado proposto por Bollerslev (1990), em que a correlação condicional é constante no tempo. ${ }^{5}$ Desta forma será possível ve-

\footnotetext{
${ }^{5}$ Racine et al. (1998) utilizaram este modelo com sucesso para três índices de açōes e seus respectivos preços futuros: NYSE Composite, SGP 500 e Toronto 35. Galvão et al. (2000) utilizaram um GARCH bivariado para testar a causalidade entre o lbovespa à vista e futuro.
} 
rificar se os investidores têm precificado as ações do Banco do Brasil com risco próximo ao dos bancos privados após a reestruturação do sistema financeiro nacional.

O restante deste artigo está assim organizado. Na segunda seção são especificadas as formulações univariada e multivariada dos modelos paramétricos aqui utilizados. Na seção três estão as descrições das características estatísticas e dos principais fatos estilizados na literatura, além das estimativas da matriz de covariância condicional e correlações para as ações do sistema financeiro. As conclusões e implicações estão na seção quatro.

\section{Metodologia}

Os modelos da família GARCH contemplam duas equações que são estimadas conjuntamente, uma que está relacionada à média condicional, e outra à variância condicional. Deve ser ressaltado que existe uma diferença na equação da média entre os modelos que não consideram a presença de $h_{t}$ nesta $(\mathrm{ARCH}$, GARCH, EGARCH e GJR), dos que consideram, como o ARCH-M e o GARCH-M, ver Engle et al. (1987).

De uma forma geral, os resíduos dos modelos, no primeiro caso, podem ser representados por 2.1:

$$
\varepsilon_{t}=R_{t}-\beta x_{t}
$$

onde $R_{t}$ são os retornos da ação e $\beta x_{t}^{\prime}$ a sua média. Para o caso dos modelos com presença da variância na equação da média, a formulação 2.2 pode ser utilizada;

$$
\varepsilon_{t}=R_{t}-\beta x_{t}^{\prime}-\delta h_{t}
$$

onde $h_{t}$ é a variância condicional, com $\varepsilon_{t} / \psi_{t-1} \sim D\left(0, \sigma_{t}^{2}\right)$ e $D$ (.) é uma função de distribuição paramétrica qualquer, que pode ser uma Normal, t-Student ou então uma GED (Generalized Error Distribution), ver Bollerslev (1987) e Nelson (1991).

Além de definir a equação da média e a distribuição dos resíduos, deve ser determinada, também, a equação da variância $(h)$. Na tabela 1 estão especificadas as formulações mais populares em finanças para o segundo momento. Vale ressaltar que estes modelos são importantes na literatura econométrica por evidenciarem algumas das características mais 
comuns em séries financeiras; caudas pesadas, aglomeração de volatilidade, persistência e o efeito assimetria. ${ }^{6}$

Tabela 1: Alguns modelos de volatilidade condicional

\begin{tabular}{cc}
\hline Modelo & Equação da Variância \\
\hline ARCH & $h_{t}=c+\sum_{i=1}^{p} \alpha_{i} \varepsilon_{t-i}^{2}$ \\
\hline GARCH & $h_{t}=c+\sum_{i=1}^{p} \alpha_{i} \varepsilon_{t-i}^{2}+\sum_{j=1}^{q} \beta_{j} h_{t-j}$ \\
\hline EGARCH & $\log \left(h_{t}\right)=c+\beta \log \left(h_{t-1}\right)+\gamma \frac{\varepsilon_{t-1}}{\sqrt{h_{t-1}}}+\alpha\left[\frac{\left|\varepsilon_{t-1}\right|}{\sqrt{h_{t-1}}}-\sqrt{\frac{2}{\pi}}\right]$ \\
\hline GJR & $h_{t}=c+\sum_{i=1}^{p} \alpha_{i} \varepsilon_{t-i}^{2}+\sum_{j=1}^{q} \beta_{j} h_{t-j}+\gamma S_{t-1}^{-} \varepsilon_{t-1}$ \\
$S_{t}^{-}=\left(\begin{array}{l}1 \text { se } \varepsilon_{t-1}<0 \\
0 \text { se } \varepsilon_{t-1} \geq 0\end{array}\right.$
\end{tabular}

A formulação GARCH apresenta significativa melhora sobre a $\mathrm{ARCH}$, porém ela não é capaz de captar o efeito assimetria devido ao fato de assumir que choques de retorno positivos e negativos de mesma magnitude produzem o mesmo efeito na volatilidade, ou seja, este modelo é simétrico. Nelson (1991) propôs o modelo EGARCH, que permite captar o efeito assimetria a partir de $\gamma<0$, onde choques de retornos positivos geram menor volatilidade do que choques de retornos negativos. Uma formulação também conhecida nesta literatura é o modelo GJR, onde a assimetria é captada a partir ${ }^{7}$ da variável $0<\gamma<1$.

A presença desta assimetria também pode ser evidenciada a partir de quatro testes, que foram propostos por Engle et al. (1993); um teste de viés de sinal, que examina o impacto de choques de retornos positivos e negativos na volatilidade, um teste de viés de sinal para retornos positivos e outro para retornos nega-

6 Ver Bollerslev et al. (1992) e Kim et al. (1994).

7 A intuição por trás do efeito assimetria é justamente determinar quanto o mercado diferencia um efeito positivo de um negativo sobre a volatilidade. Ver Engle et al. (1993) para a assimetria dos retornos, e Glosten et al. (1993) para a formulação do modelo GJR. 
tivos, para evidenciar a diferença de magnitude entre eles e, por fim, um teste conjunto dos três efeitos. Assim, além destes testes medirem se há realmente uma diferença entre choques positivos e negativos, também é possível verificar se há diferença na magnitude deste impacto.

Um outro fato estilizado a ser investigado é a persistência. No modelo $\operatorname{GARCH}(p, q)$ esta é dada por $\sum_{i=1}^{p} \alpha_{i}+\sum_{j=1}^{q} \beta_{j}$ onde, se a soma for igual a 1 , então tem-se um modelo $\operatorname{IGARCH}(p, q)$. No modelo EGARCH a persistência é dada por $\beta$ e no GJR por $\sum_{i=1}^{p} \alpha_{i}+\sum_{j=1}^{q} \beta_{j}+\gamma / 2$. Por fim tem-se a aglomeração de volatilidade, que no modelo EGARCH é captada por $\alpha>0$.

É importante destacar que a estimativa dos parâmetros, que estão presentes tanto na equação da média quanto da variância nestes modelos, é feita por um processo iterativo a partir da maximização da função de distribuição especificada.

Nos últimos anos intensificaram-se as pesquisas com modelos de volatilidade desterminística multivariados. Estes, mesmo gerando ganhos de informação e eficiência em relação aos modelos univariados, esbarram em alguns problemas de estimação. Vale ressaltar que a idéia da formulação multivariada é tentar capturar a dependência temporal que existe nas covariâncias e variâncias condicionais e, para tanto, algumas hipóteses devem ser feitas na matriz de covariância $H_{t}$, que é gerada.

Dependendo de quais são estas restrições, diferentes números de parâmetros podem ser estimados, e informações diversas podem ser obtidas. Na literatura econométrica, várias são as representações existentes que inferem sobre estas restrições, e diferentes aplicaçōes foram feitas no mercado financeiro, ${ }^{8}$ sendo que o uso de cada formulação irá depender do objetivo proposto.

Bollerslev (1990) utilizou um modelo no qual as volatilidades e as covariâncias entre estas são variantes no tempo, mas a cor-

8 Para uma breve discussão sobre os modelos multivariados, consultar Bollerslev et al. (1994), Gouriéroux (1996) e Bollerslev et al. (1992). 
relação condicional é constante. Seja $R_{t}$ um vetor $n X I$ de retornos. Então, a equação 2.1 pode ser expressa por 2.3:

$$
\varepsilon_{i t}=R_{i t}-\beta_{i} x_{i t}
$$

com $\varepsilon_{t} / \psi_{t-1} \sim N\left(0, H_{t}\right)$, onde $\varepsilon_{t}$ é um vetor $n x I$ de inovações, $i=1, \ldots, n$, e os elementos da diagonal da matriz de variância condicional $\mathrm{H}_{t}$ são dados, no caso do $\operatorname{GARCH}(p, q)$, por:

$$
h_{i, i, t}=C_{i}+\sum_{p=1}^{P} \alpha_{i, p} \varepsilon_{i, i, t-p}^{2 .}+\sum_{q=1}^{Q} \beta_{i, q} h_{i, i, t-q}+\sum_{l=1}^{L} d_{i, t} X_{l, t}
$$

onde $X$ é um vetor de variáveis exógenas, e os elementos fora da diagonal de $\mathrm{H}_{t}$ são dados por 2.5 , onde $\rho$ é a correlação condicional: ${ }^{9}$

$$
H_{i j}=\rho_{i j}\left[\{H\}_{i i}\{H\}_{i j}\right]^{1 / 2}
$$

Como pode ser visto, nesta abordagem, a matriz de covariância condicional é parametrizada para ser proporcional ao produto dos correspondentes desvios-padrão condicional. Desta forma, considerando a estimativa com apenas duas variáveis, a equação 2.4 resulta em um conjunto de equações para as volatilidades e a correlação, tal como:

$$
\begin{aligned}
& h_{11, t}=c_{11}+\alpha_{11} \varepsilon_{1, t-1}^{2}+\beta_{11} h_{11, t-1} \\
& h_{22, t}=c_{22}+\alpha_{22} \varepsilon_{21, t-1}^{2}+\beta_{22} h_{22, t-1} \\
& h_{12, t}=\rho_{12}\left(h_{11, t} h_{22, t}\right)^{1 / 2}
\end{aligned}
$$

onde $c_{11}, c_{22}, \rho_{12}, \alpha_{11}, \alpha_{22}, \beta_{11}$ e $\beta_{22}$ são estimados por máxima verossimilhança. $\mathrm{O}$ modelo de correlação constante é particularmente atraente por usar um processo de estimação simples, possibilitando que se mensure, além do comportamento da volatilidade no tempo, a correlação entre a volatilidade dos ativos, que em 2.6 é dada por $\rho_{12}$ ou seja, $\rho_{i j}$ em 2.5. Assim, estimativas significantes de $\rho_{i j}$ indicam que as volatilidades variantes no tempo entre os ativos $i$ e $j$ são correlacionadas temporalmente. A medida da persistência, neste caso, se dá através de $\sum \alpha_{i j}+\sum \beta_{i j}$ ou seja, no caso de 2.6 , por $\alpha_{11}+\beta_{11}$ para a volatilidade do ativo 1, e $\alpha_{22}+\beta_{22}$ para a volatilidade do ativo 2 .

9 Este modelo foi usado por Bollerslev (1990), Baillie et al (1990), Kroner et al. (1993) e Login et al. (1995). 


\section{Resultados empíricos}

$\mathrm{Na}$ primeira parte desta seção, as séries de retornos de quatro ações do setor bancário brasileiro, Banco do Brasil, Itaú, Bradesco e Unibanco, que compreendem o período de 2 de agosto de 1994 a 2 de outubro de 2000, são analisadas com o intuito de se verificar a existência de aglomeração de volatilidade, assimetria e persistência. Para tanto são utilizados diversos modelos univariados da família GARCH. Os gráficos de 1 a 4 mostram a evolução dos preços destas ações neste período $^{10}$ e a tabela 2 apresenta um sumário estatístico dos retornos para todas as séries.

Como pode ser visto, todas têm média próxima de zero, não sendo rejeitada a hipótese de que esta é igual a zero. O Banco que apresenta a menor média e o maior desvio-padrão é o Banco do Brasil, ao passo que a ação do Itaú é a que tem a maior média 0,0015 , e o menor desvio padrão $0,028 .{ }^{11}$

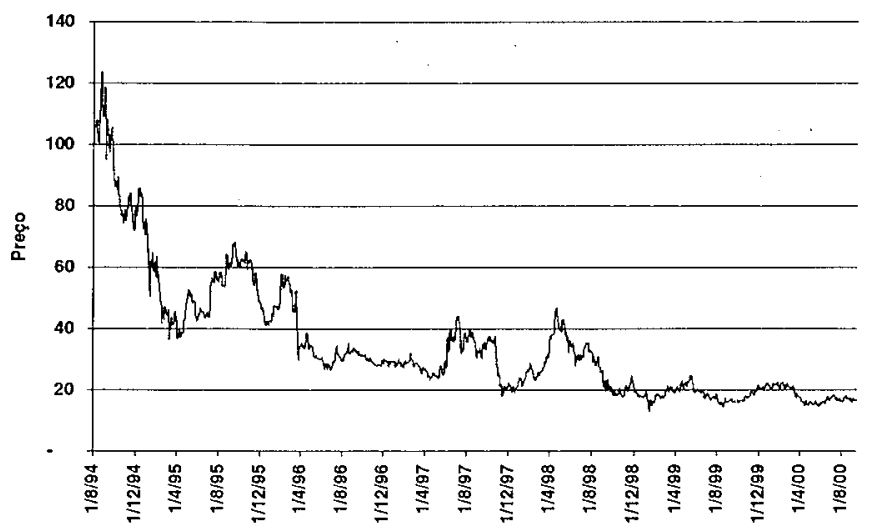

\section{Gráfico 1: Banco do Brasil - BBAS4}

\footnotetext{
${ }^{10}$ Foi criado para cada série um índice de base fixa. Nos modelos univariados, nos dias em que não ocorreu negociação com a ação, aqueles não foram preenchidos.

${ }^{11}$ Foi feito um teste $\mathrm{t}$ para a diferença de média entre as ações do sistema financeiro, $\mathrm{e}$ os valores encontrados para o teste unicaudal revelam ser a média do Banco do Brasil a menor, seguida de Unibanco, Bradesco e, por fim, Itaú.
} 


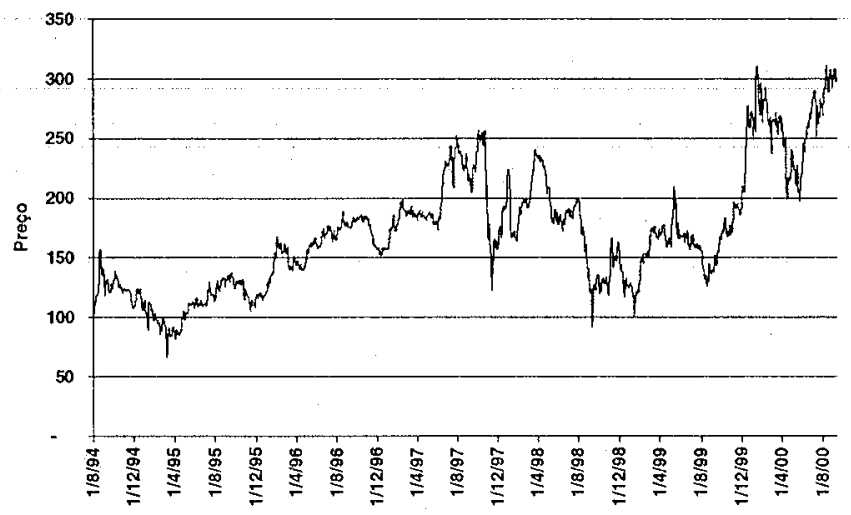

\section{Gráfico 2: Bradesco - BBDC4}

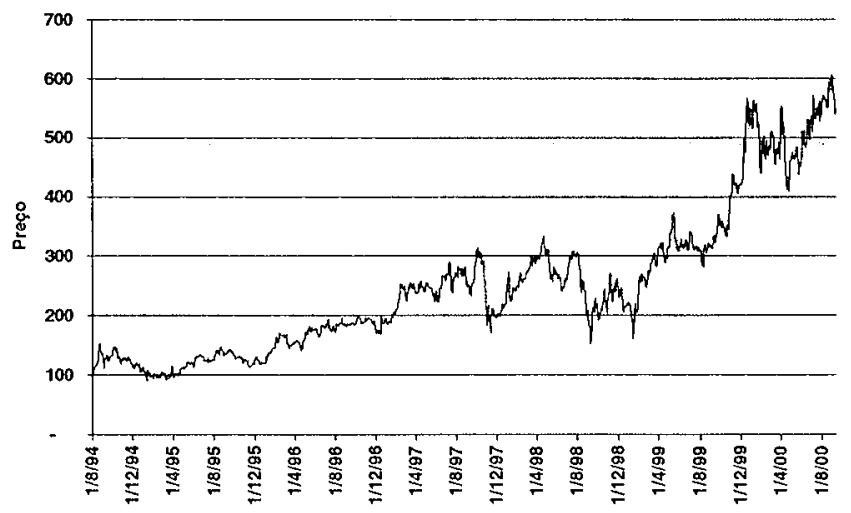

\section{Gráfico 3: Itaú - ITAÚu}

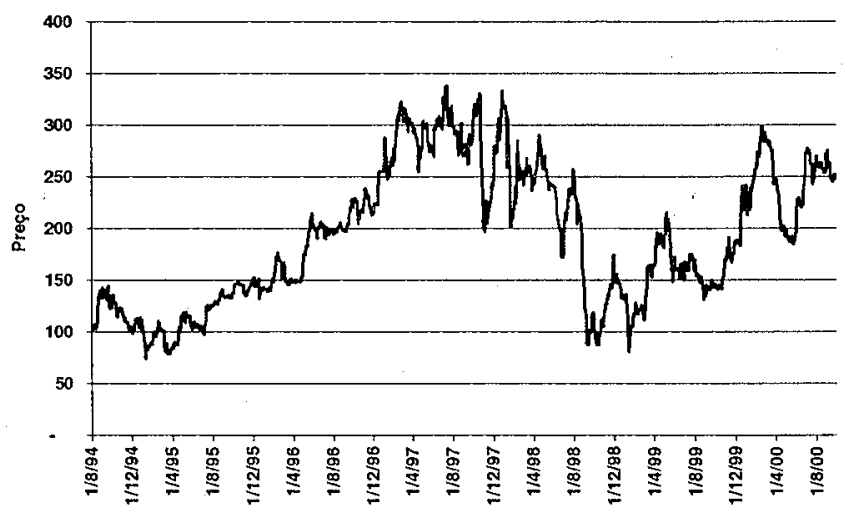

\section{Gráfico 4: Unibanco - UBBR4}


Tabela 2: Sumário estatístico dos retornos

\begin{tabular}{cccccccc}
\hline Ações & Média & Desv. Pad. & Assimetria & Curtose & J-B & Q(5) & QS(5) \\
\hline BBAS4 & $-0,0005$ & 0,037 & $-0,62^{\mathrm{a}}$ & $9,14^{\mathrm{a}}$ & $5372^{\mathrm{a}}$ & $13,78^{\mathrm{b}}$ & $40,65^{\mathrm{a}}$ \\
\hline BBDC4 & 0,0011 & 0,030 & $0,21^{\mathrm{a}}$ & $9,24^{\mathrm{a}}$ & $5444^{\mathrm{a}}$ & $30,5^{\mathrm{a}}$ & $217,4^{\mathrm{a}}$ \\
\hline ITAU4 & 0,0015 & 0,028 & $0,13^{\mathrm{a}}$ & $3,17^{\mathrm{a}}$ & $645^{\mathrm{a}}$ & $58,2^{\mathrm{a}}$ & $259,9^{\mathrm{a}}$ \\
\hline UBBR4 & 0,0010 & 0,034 & $-0,07^{\mathrm{c}}$ & $4,66^{\mathrm{a}}$ & $1318^{\mathrm{a}}$ & $17,3^{\mathrm{a}}$ & $323,3^{\mathrm{a}}$ \\
\hline
\end{tabular}

Nota: As hipóteses que estão sendo testadas $\left(\mathrm{H}_{0}\right)$ são: média $=0$, assimetria $=0$, curtose \pm 0 e teste de autocorrelação. a significante menor que $1 \%$, b entre $1 \%$ e $5 \%$, c entre $5 \%$ e $10 \%$ e d acima de $10 \%$. J-B é a estatística Jarque-Bera, Q(.) é a estatistica Ljung Box para os retornos e QS(.) é a mesma estatística para o quadrado dos retornos.

Apesar de valores próximos a zero, pode ser constatado que todas as séries possuem problema de assimetria e curtose, excetuando as do Unibanco, o que indica a presença de caudas mais pesadas que a distribuição normal. Isto significa que existe uma probabilidade maior, tanto de grandes perdas (assimetria à esquerda), quanto de elevados retornos (assimetria à direita). Além do mais, a probabilidade de ocorrer um retorno em torno da média também se mostra mais alta.

O fato de o valor da curtose, para muitas séries, estar bem acima de três, significa que a cauda da distribuição dos retornos aqui é muito maior do que na distribuição normal. Vale ressaltar que números muito grandes para a curtose surgem do fato de que este coeficiente é bastante sensivel a retornos elevados.

A existência de uma distribuição leptocúrtica pode ser comprovada pelo teste de normalidade de Jarque-Bera, onde a distribuição de todos os retornos de ações aqui consideradas não é normal. ${ }^{12}$ A estatística (Q) Ljung-Box, especificada na tabela como $Q(5)$, revela, para todas as séries, a existência de autocorrelação serial altamente significante, e a estatística QS(5), para analisar a dependência não-linear dos retornos ao quadrado, também é significante, além do fato de este resultado sinalizar a presença de agrupamento de variância, variance clustering.

Vale ressaltar que esta, por sua vez, pode estar sendo causada pela presença de heteroscedasticidade condicional auto-regressiva,

12 A série do Unibanco não teve problema de assimetria, mas o teste de Jarque-Bera acusou a existência de nāo-normalidade. 
sugerindo que sejam analisadas as dependências no segundo momento dos resíduos para cada série univariada. Na modelagem dos retornos condicionais com presença de heteroscedasticidade foram colocadas duas dummies de outlier na equação da média ${ }^{13}$ onde, após vários testes $\operatorname{ARMA}(p, q)$ conjuntamente com um $\operatorname{GARCH}(p, q)$, chega-se à conclusão que o melhor modelo é o que considera uma defasagem, tanto para $\alpha$, quanto para $\beta .{ }^{14}$

Tabela 3: Dummies utilizadas para os retornos em cada série

\begin{tabular}{ccccc}
\hline & BBAS4 & BBDC4 & ITAÚ4 & UBBR4 \\
\hline D1 & $r>0,10$ & $r>0,12$ & $r>0,08$ & $r>0,10$ \\
\hline D2 & $r<-0,12$ & $r<-0,12$ & $r<-0,08$ & $r<-0,10$ \\
\hline
\end{tabular}

Nota: D1 é a dummy 1, e D2 a dummy 2, r são os retornos das ações.

São estimados dez modelos univariados diferentes; um ARCH-M e um GARCH-M para verificar se há a incidência de risco do ativo no seu retorno; um GARCH com distribuição normal, t-Student e GED (Generalized Error Distribution), que mostra tanto a persistência de choques na volatilidade quanto a existência de uma distribuição não-normal dos retornos. O modelo IGARCH é testado para verificar se $\alpha+\beta=1$ (persistência infinita). Os modelos EGARCH e EGARCH-t revelam a existência de aglomeração, efeito assimetria e persistência e, por fim, os modelos GJR e GJR-t a persistência e o efeito assimetria. Nas tabelas 4 e 5 estão apresentados os resultados.

Nas estimativas do modelo $\mathrm{ARCH}-\mathrm{M}$, pode ser visto que não há incidência da volatilidade na determinação da média dos retornos para todas as séries, com exceção de BBDC4, a 1\% e ITAÚ4 a $4 \%$. No GARCH-M, duas séries apresentaram a existência deste efeito, ITAÚ4 a $2 \%$ e UBBR4 a $4 \%$, onde o coeficiente para a volatilidade na equação da média foi de 0,056 e 0,053, respectiva-

${ }^{13}$ A dummy1 representa retornos muito elevados e a dummy2 é para retornos excessivamente negativos. Estas dummies se mostraram significativas em todas as séries e modelos testados.

${ }^{14}$ A estrutura ARMA, ou seja, a equação da média para cada ação, ficou assim especificada: BBAS4, BBDC4, ITAÚ4 e UBBR4 um ARMA $(1,0)$; a série do Unibanco apresentou como significativa a defasagem $p=2$ mas, para critério de comparaçăo com os demais modelos, manteve-se apenas uma defasagem para o coeficiente da variância condicional defasada $p$. Para todas as estimativas foi utilizado o algoritmo BHHH. 
mente, evidenciando que um aumento da volatilidade afetà de forma positiva os retornos destas duas ações. Já em BBDC4, este foi significante apenas a $18 \%$.

Portanto, podemos concluir que os retornos dos ativos do sistema financeiro privado (BBDC4, ITAÚ4 e UBBR4) sofrem influência direta do aumento do risco, o que não ocorre com o banco estatal BBAS4. Esta característica comprova que, de forma geral, o mercado diferencia de forma clara os bancos privados do banco estatal.

Tabela 4: Modelos univariados de volatilidade condicional

\begin{tabular}{ccccccccccc}
\hline & \multicolumn{2}{c}{ ARCH(1)-M } & \multicolumn{2}{c}{ GARCH(1,1) } & \multicolumn{2}{c}{ GARCH(1,1)-t } & \multicolumn{2}{c}{ GARCH(1,1)-GED } & \multicolumn{2}{c}{ IGARCH(1,1) } \\
\hline AÇÕES & $\alpha$ & $\mathbf{M}$ & $\boldsymbol{\alpha}+\beta$ & $\lambda$ & $\boldsymbol{\alpha}+\boldsymbol{\beta}$ & $\mathbf{d}$ & $\alpha+\boldsymbol{\beta}$ & $\mathbf{d}$ & $\alpha$ & $\beta$ \\
\hline BBAS4 & 0,189 & $-0,02 \mathrm{~d}$ & $0,963 \mathrm{~m}$ & 20 & 0,977 & 9,28 & 0,970 & 1,47 & 0,060 & 0,940 \\
\hline BBDC4 & 0,378 & 0,27 & $0,973 \mathrm{~m}$ & 26 & 0,972 & 5,96 & 0,972 & 1,24 & 0,146 & 0,854 \\
\hline ITAÚ4 & 0,145 & $0,05 \mathrm{~b}$ & 0,940 & 12 & 0,951 & 6,94 & 0,947 & 1,26 & 0,0509 & 0,949 \\
\hline UBBR4 & 0,198 & $0,04 \mathrm{~d}$ & 0,989 & 67 & 0,999 & 3,34 & 0,999 & 0,78 & 0,049 & 0,951 \\
\hline
\end{tabular}

Nota: A letra m revela a não existência de $\mathrm{GARCH}(1,1)$-m. a significante menor que $1 \%$, b entre $1 \%$ e $5 \%$, c entre $5 \%$ e $10 \%$, d acima de $10 \%$. O modelo GARCH-GED para ARCZ6 não convergiu. Em GARCH-t, d representa os graus de liberdade e, em GARCH-GED, d é o parâmetro de escala.

Tabela 5: Modelos univariados de volatilidade condicional

\begin{tabular}{ccccccccccc}
\hline & \multicolumn{3}{c}{ EGARCH(1,1) } & \multicolumn{3}{c}{ EGARCH(1,1)-t } & \multicolumn{2}{c}{ GJR(1,1) } & \multicolumn{2}{c}{ GJR(1,1)-t } \\
\hline AÇÕES & $\alpha$ & $\beta$ & $\gamma$ & $\alpha$ & $\beta$ & $\gamma$ & $\alpha+\beta$ & $\gamma$ & $\alpha+\beta$ & $\gamma$ \\
\hline BBAS4 & 0,137 & 0,955 & $-0,007 d$ & 0,126 & 0,923 & $-0,01$ & 0,968 & $0,013 d$ & 0,975 & $0,01 d$ \\
\hline BBDC4 & 0,304 & 0,938 & $-0,058$ & 0,432 & 0,878 & $-0,08$ & 0,972 & 0,096 & 0,969 & 0,12 \\
\hline ITAU4 & 0,228 & 0,908 & $-0,045$ & 0,253 & 0,918 & $0,05 d$ & 0,923 & 0,071 & 0,944 & $0,07 \mathrm{c}$ \\
\hline UBBR4 & 0,124 & 0,973 & $0,014 d$ & 0,288 & 0,971 & $0,02 d$ & 0,980 & $0,017 \mathrm{c}$ & 0,999 & $0,02 \mathrm{~d}$ \\
\hline
\end{tabular}

Nota: a significante menor que $1 \%$, b entre $1 \%$ e $5 \%$, c entre $5 \%$ e $10 \%$, d acima de $10 \%$

Nos modelos com distribuições não-Normal, pode ser visto que o valor de $d<2$ no GARCH-GED para todas as ações indica que estas séries contêm, relativamente, um grande número de retornos (positivos e negativos), que ocorrem distante da média da distribuição, comprovando a existência de caudas mais densas. Além disso, todas as demais séries apresentaram como significante o parâmetro 
d, ou seja, no geral é esperado que modelos com caudas mais pesadas do que a normal melhor se adaptem aos dados.

Em relação à persistência, dada pela soma dos coeficientes $\alpha$ e $\beta$ no modelo GARCH, estas ${ }^{15}$ ficaram acima de 0,94 . Isso significa que o tempo necessário para absorver todo o efeito de um choque na volatilidade é alto. No geral, as formulações GARCHt e GED aumentaram o valor da persistência para todas as ações. Extenuando UBBR4 que tem uma persistência média de 0,987, as duas outras ações do setor privado apresentaram persistências menores do que a do banco estatal.

Comparativamente à persistência encontrada em sete ações utilizadas em Almeida et al. (1999), a partir da estimação de um GARCH sem dummies na equação da variância, ${ }^{16}$ nota-se que BBDC4, ITAÚ4 e UBBR4 apresentaram, aqui, persistência um pouco maior.

No teste de Ljung-Box para o quadrado dos resíduos normalizados, apenas na formulação ARCH-M nota-se a existência de autocorrelação em todas as séries, resultado que não é encontrado nos demais modelos.

$\mathrm{Na}$ formulação EGARCH pode ser constatada a existência da aglomeração na volatilidade a partir de $\alpha>0$ em todas as ações, sendo esta maior para a série BBDC4. Além disso, o coeficiente $\gamma$ confirma a presença de efeito assimetria de choques, que não é significativo apenas em BBAS4 e UBBR4. Para todas as ações, extenuando BBAS4, o uso do modelo EGARCH-t aumenta o valor de $\alpha$ (assimetria), e faz com que resultados ambíguos sejam encontrados para $\gamma$ onde, em seis retornos, este coeficiente não se mostra significante. Também na formulação GJR, a inclusão da distribuição $t$-Student faz com que, em seis séries de retornos de ações, o coeficiente do efeito assimetria fique não significativo.

As ações que chamam a atenção, neste caso, são BBAS4 e UBBR4, merecendo uma maior verificação da presença ou não deste efeito. Por fim é feito um teste de diagnóstico para medir se

15 A meia-vida mede o período de tempo necessário para que o efeito de um choque na volatilidade diminua até a metade, e é dada por $\lambda=1-[\log 2 / \log \delta]$, onde $\delta$ é a persistência. ${ }^{16}$ Os resultados encontrados por Almeida et al. (1999) não consideram a presença de dummy na média, tal como feito neste trabalho. Além do mais, os pacotes estatísticos utilizados são diferentes. 
há diferença entre os choques de retornos positivos e negativos, tal como proposto por Engle (1993), e seus resultados se encontram na tabela $6 .{ }^{17}$

Tabela 6: Resultado do teste de diagnóstico para a assimetria

\begin{tabular}{|c|c|c|c|c|c|c|c|c|c|c|c|c|}
\hline & \multicolumn{4}{|c|}{ GARCH } & \multicolumn{4}{|c|}{ EGARCH } & \multicolumn{4}{|c|}{ GJR } \\
\hline Ações & $\begin{array}{l}\text { Sign } \\
\text { Bias }\end{array}$ & $\begin{array}{l}\text { Negative } \\
\text { Size }\end{array}$ & $\begin{array}{c}\text { Positive } \\
\text { Size }\end{array}$ & $\begin{array}{l}\text { Joint } \\
\text { Test }\end{array}$ & $\begin{array}{l}\text { Sign } \\
\text { Bias }\end{array}$ & $\begin{array}{l}\text { Negative } \\
\text { Size }\end{array}$ & $\begin{array}{c}\text { Positive } \\
\text { Size }\end{array}$ & $\begin{array}{l}\text { Joint } \\
\text { Test }\end{array}$ & $\begin{array}{l}\text { Sign } \\
\text { Bias }\end{array}$ & $\begin{array}{c}\text { Negative } \\
\text { Size }\end{array}$ & $\begin{array}{c}\text { Positive } \\
\text { Size }\end{array}$ & $\begin{array}{l}\text { Joint } \\
\text { Test }\end{array}$ \\
\hline BBAS4 & $-1,5$ & $-1,09$ & 0,26 & 1,39 & $-1,5$ & $-1,09$ & 0,68 & 1,9 & $-1,5$ & $-0,83$ & 0,38 & 1,4 \\
\hline BBDC4 & $-1,6^{c}$ & $-2,88^{a}$ & 0,00 & $2,79^{b}$ & $-1,8^{b}$ & $-2,70^{b}$ & 0,47 & $2,3^{c}$ & $-1,9^{b}$ & $-2,2^{b}$ & 0,40 & $2,3^{b}$ \\
\hline ITAÚ4 & 1,59 & 0,06 & 0,67 & 1,26 & 1,5 & 0,85 & 0,72 & 0,79 & $1,7^{\circ}$ & 0,71 & 0,90 & 0,98 \\
\hline UBBR4 & $-0,4$ & $-1,87^{\circ}$ & $1,86^{\mathrm{b}}$ & $2,41^{b}$ & $-0,8$ & $-1,83^{b}$ & $1,93^{b}$ & $2,8^{\mathrm{b}}$ & $-0,3$ & $-1,70^{\circ}$ & $2,21^{b}$ & $2,7^{b}$ \\
\hline
\end{tabular}

Nota: a significativo menor que $1 \%$, b entre $1 \%$ e $5 \%$ e c entre $5 \%$ e $10 \%$.

Como pode ser visto, BBAS4 não apresenta diferença tanto no sinal do retorno - se positivo ou negativo - quanto na magnitude do choque. Já as outras ações que suscitavam dúvida anteriormente acusaram a presença desta assimetria. Vale ressaltar que apenas a relacionada ao banco estatal não apresenta assimetria na distribuição dos choques de retornos, o que reforça a tese de que as ações deste banco oferecem menor risco, uma vez que os investidores parecem ser indiferentes entre choques positivos e negativos.

Em BBDC4, o teste mostra que a causa do grande efeito na volatilidade são os maiores choques de retornos negativos. Em ITAÚ4 podemos apenas admitir a presença de assimetria na distribuição dos choques, e em UBBR4 há uma certa dificuldade em se diferenciar este efeito, devido a significância tanto para choques positivos, quanto para negativos.

O próximo passo é analisar estas ações em conjunto com o intuito de verificar se existe uma correlação da percepção de risco entre o setor público e privado, e se, com o início das privatizações dos bancos estatais, esta relação se modificou. ${ }^{18}$

${ }_{17}$ Os testes são o Sign Bias - teste de viés de sinal; Negative Size - teste de viés de sinal negativo; Positive Size - teste de viés de sinal positivo; e Joint Test - teste conjunto para verificar a presença dos três efeitos.

${ }^{18}$ Nas formulações multivariadas, quando uma série não teve dia de negociaçāo e a outra sim, este dia foi excluído da amostra. 
Na comparação feita entre os modelos a partir do valor do máximo do log da função de verossimilhança e do critério de Akaike, seleciona-se a formulação GARCH-GED como a melhor. A tabela 7 mostra os resultados para estas duas estatísticas. ${ }^{19}$

Tabela 7: Critérios de comparação maximo do log da verossimilhança e Akaike

\begin{tabular}{|c|c|c|c|c|c|c|c|c|}
\hline & \multicolumn{2}{|c|}{ BBAS4 } & \multicolumn{2}{|c|}{ BBDC4 } & \multicolumn{2}{|c|}{ TTAÚ4 } & \multicolumn{2}{|c|}{ UBBR4 } \\
\hline & Log & AIC & Log & AIC & Log & AIC & $\log$ & AIC \\
\hline$A R C H(1) M$ & 3036,74 & 763,01 & 3379,42 & 253,48 & 3502,79 & $-115,92$ & 3151,17 & 218,39 \\
\hline $\operatorname{GARCH}(1,1)-M$ & 3068,29 & 765,01 & 3429,57 & 255,48 & 3537,77 & $-113,92$ & 3203,97 & 220,39 \\
\hline GARCH $(1,1)$ & 3068,25 & 763,01 & 3428,48 & 253,48 & 3035,30 & $-115,92$ & 3201,87 & 218,39 \\
\hline $\operatorname{GARCH}(1,1)-\mathrm{t}$ & 3080,19 & 765,01 & 3455,95 & 255,48 & 3550,43 & $-113,92$ & 3265,24 & 220,39 \\
\hline GARCH(1,1)-GED & 3083,05 & 765,01 & 3464,86 & 255,48 & 3565,29 & $-113,92$ & 3330,57 & 220,39 \\
\hline IGARCH(1,1) & 3061,53 & 761,01 & 3426,00 & 251,48 & 3528,76 & $-117,92$ & 3196,92 & 216,39 \\
\hline $\operatorname{EGARCH}(1,1)$ & 3065,31 & 765,01 & 3434,75 & 255,48 & 3543,49 & $-113,92$ & 3202,67 & 220,39 \\
\hline $\operatorname{EGARCH}(1,1)-\mathrm{t}$ & 3080,19 & 767,01 & 3461,44 & 257,48 & 3555,78 & $-111,92$ & 3266,85 & 222,39 \\
\hline GJR(1,1) & 3068,44 & 765,01 & 3435,08 & 255,48 & 3537,46 & $-113,92$ & 3202,72 & 220,39 \\
\hline GJR(1,1)-t & 3080,40 & 767,01 & 3460,98 & 257,48 & 3552,00 & $-111,93$ & 3265,45 & 222,39 \\
\hline
\end{tabular}

Nota: Log é o máximo do log da função de verossimilhança e AIC é o critério de comparação de Akaike.

Os gráficos de 5 a 8 mostram as estimativas de volatilidade univariada deste modelo para estas ações considerando toda a amostra, onde foram sinalizadas as quatro crises financeiras internacionais, México, Ásia, Rússia e Brasil.

19 Em todos os modelos, a comparação pelo log seleciona o GARCH(1,1)-GED. Já AiC seleciona o IGARCH $(1,1)$ em BBAS4 e BBDC4 e UBBR4 e, para ITAÚ4, o modelo $\operatorname{GARCH}(1,1)-\mathrm{t}$. 


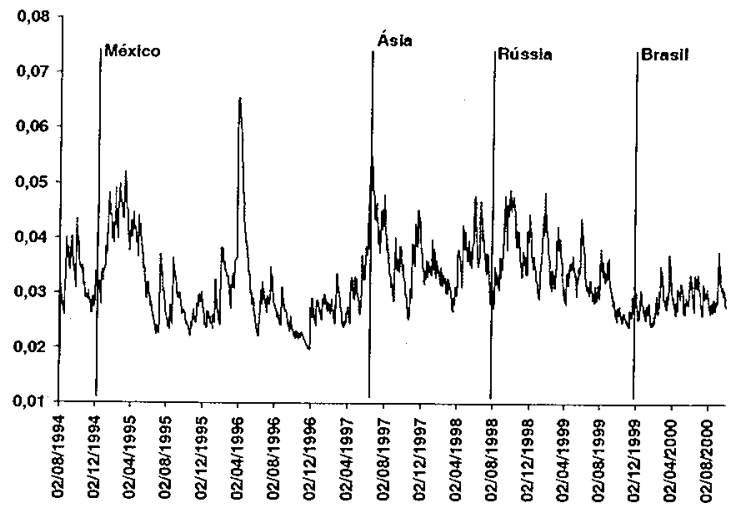

\section{Gráfico 5: hBBAS4}

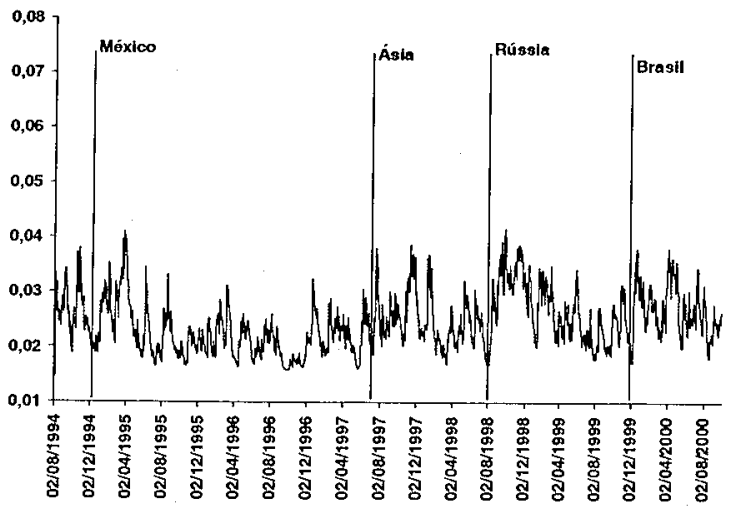

\section{Gráfico 6: hBBDC4}

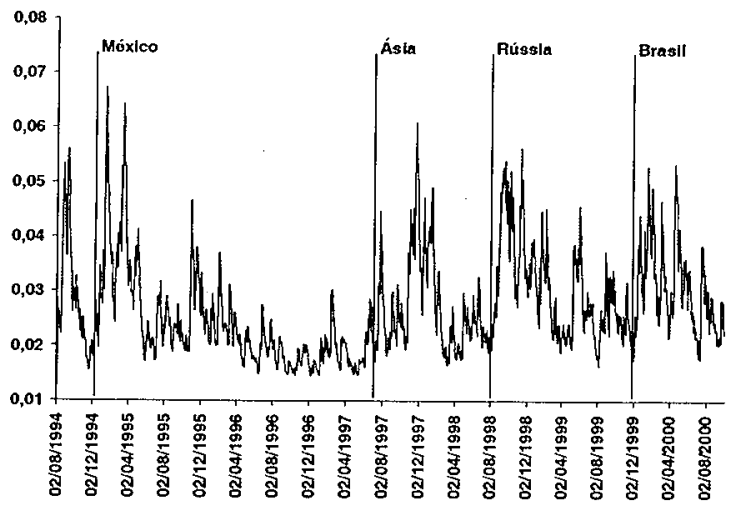

\section{Gráfico 7: hITAÚ4}




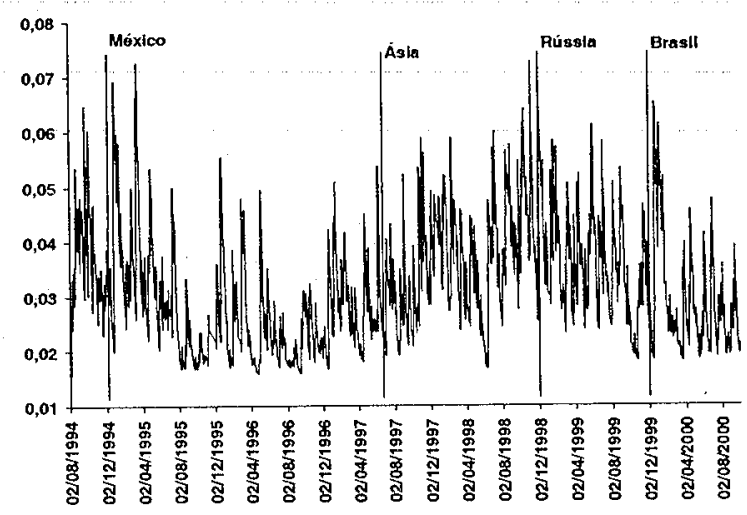

\section{Gráfico 8: hUBBR4}

A partir de uma análise visual dos gráficos, é possível concluir que UBBR4 é a ação que demonstra ter o maior intervalo de variação para a volatilidade, e ITAÚ4, o menor, ${ }^{20}$ resultado que pode ser comprovado pelo tamanho do desvio-padrão de $h_{i}$ e a distância entre a maior e a menor volatilidade, que estão mostrados na tabela 8.

Tabela 8: Estatísticas para as volatilidades estimadas para toda a amostra

\begin{tabular}{ccccc}
\hline & Média & Desvio padrão & Maior & Menor \\
\hline hBBAS4 & 0.03267 & 0.006770 & 0,065520 & 0,01793 \\
\hline hBBDC4 & 0.027021 & 0.009212 & 0.06733 & 0.012702 \\
\hline hITAÚ4 & 0.024481 & 0.005306 & 0.04161 & 0.014528 \\
\hline hUBBR4 & 0,03158 & 0,010690 & 0,07260 & 0,01560 \\
\hline
\end{tabular}

O próximo passo é a estimação de um modelo multivariado, para tentar determinar se existe alguma correlação entre a volatilidade destas quatro ações. A maximização do log da função de verossimilhança, neste caso, é feita a partir da hipótese de distribuição normal, onde são utilizadas as equações 2.3-2.5, com $p=q=1$. As estimativas são feitas aos pares para as quatro ações do sistema financeiro, em um total de seis combinações, pois a utilização de todas as variáveis em apenas um modelo implica a consideração de um número muito grande de coeficientes, tor-

${ }^{20}$ Nos quatro gráficos as escalas são de mesma magnitude. 
nando a convergência da função de verossimilhança difícil de ser encontrada. ${ }^{21}$

Inicialmente são obtidos os resultados para o período completo das séries (agosto de 1994 a outubro de 2000), mostrados na tabela 9, onde a diagonal principal representa as persistências e, a diagonal superior, as correlações.

Tabela 9: Correlações e persistência para toda a amostra

\begin{tabular}{ccccc}
\hline & BBAS4 & BBDC4 & ITAÚ4 & UBBR4 \\
\hline BBAS4 & 0,957 & 0,337 & 0,309 & 0,173 \\
\hline BBDC4 & - & 0,966 & 0,513 & 0,291 \\
\hline ITAÚ4 & - & - & 0,886 & 0,229 \\
\hline UBBR4 & - & - & - & 0,988 \\
\hline
\end{tabular}

Como pode ser visto, todas as correlações possuem sinal positivo mas com valores baixos, ${ }^{22}$ onde a maior é dada por 0,513 , e a menor 0,173 , refletindo que, no sistema financeiro, BBDC4 e ITAÚ4 são as instituições que possuem a mais elevada correlação. Isto pode estar ocorrendo devido ao fato de serem estas as duas maiores instituições privadas do sistema bancário.

Por outro lado, a menor correlação encontrada é dada por BBAS4 e UBBR4, que pode estar sendo causada pela baixa liquidez destas ações. Cabe salientar que UBBR4 é a ação cuja volatilidade tem a menor correlação com todas as demais. Por fim, todas as persistências que foram encontradas no modelo multivariado são menores do que as obtidas para o caso univariado.

Com a hipótese de correlação condicional constante, então deve-se ter que $\frac{\hat{\varepsilon}_{i t} \hat{\varepsilon}_{j t}}{\sqrt{\hat{h}_{i i t} \hat{h}_{j j t}}}, \dot{\neq} \neq j$, é não autocorrelacionado. Mas, o teste Ljung-Box feito para vinte lags, mostra que existe esta autocorrelação para tođas as estimativas, o que nos leva a crer que, realmente, a correlação entre os ativos no sistema financeiro não é constante ao longo do tempo, pelo menos durante o período aqui considerado.

${ }^{21}$ O modelo de correlaçăo constante foi testado para as quatro variáveis em conjunto, mas não convergiu. Neste caso, o número de parâmetros passou de nove, no caso de duas variáveis, para 30.

${ }^{22}$ A estatística $t$ demonstra ser todas significativas 


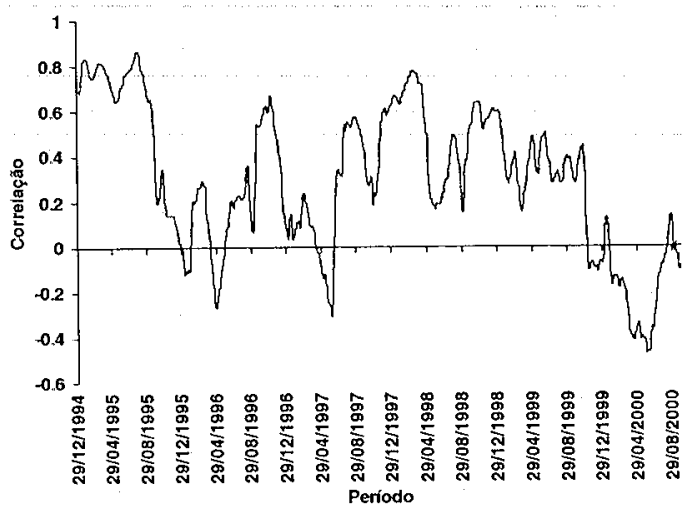

\section{Gráfico 9: hBBAS4 e hBBDC4}

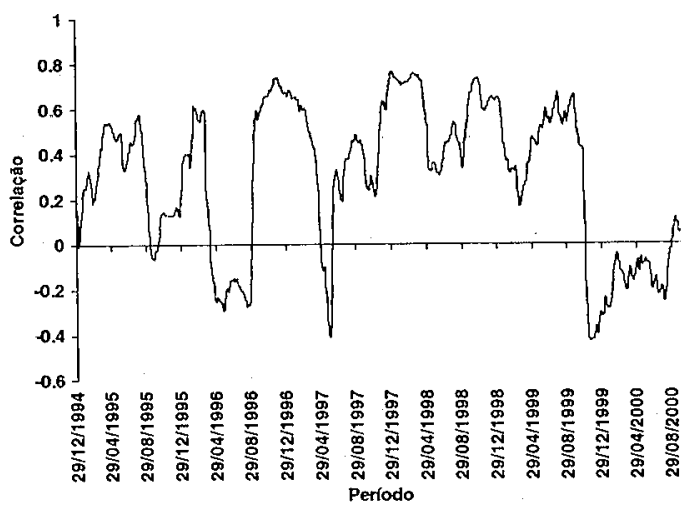

\section{Gráfico 10: hBBAS4 e hITAÚ4}

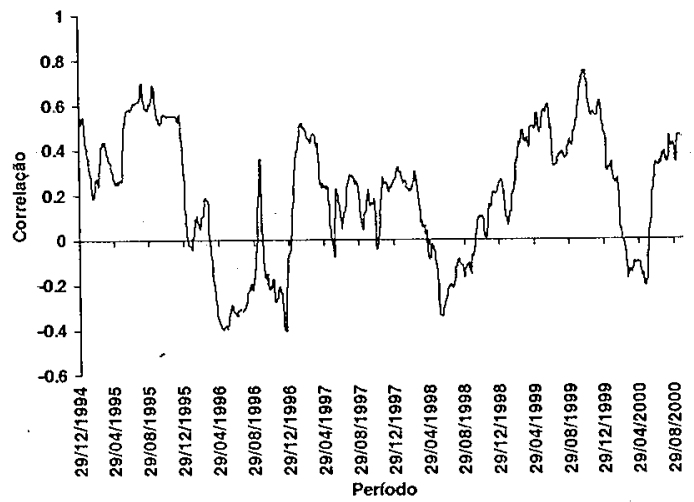

\section{Gráfico 11: hBBAS4 e hUBBR4}




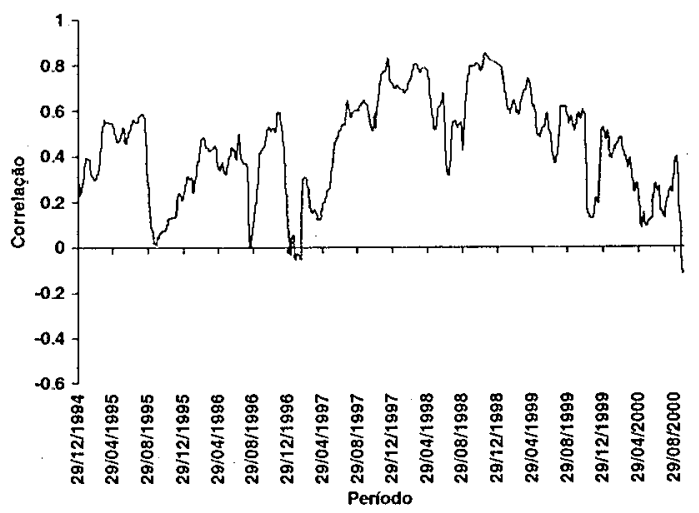

\section{Gráfico 12: hBBDC4 e hITAÚ 4}

O cálculo do coeficiente de correlação simples para a volatilidade estimada do modelo GARCH-GED, considerando uma janela de 100 dados, nos mostra que realmente esta não parece ser constante ao longo do tempo, como pode ser visto nos gráficos de 9 a $14 . .^{23}$

Vale ressaltar que, dado que nos últimos seis anos, o sistema financeiro passou por uma grande reestruturação para testar se realmente ocorreu uma mudança estrutural entre a correlação da volatilidade das ações dos bancos, o mesmo modelo anterior é estimado para dois momentos distintos.

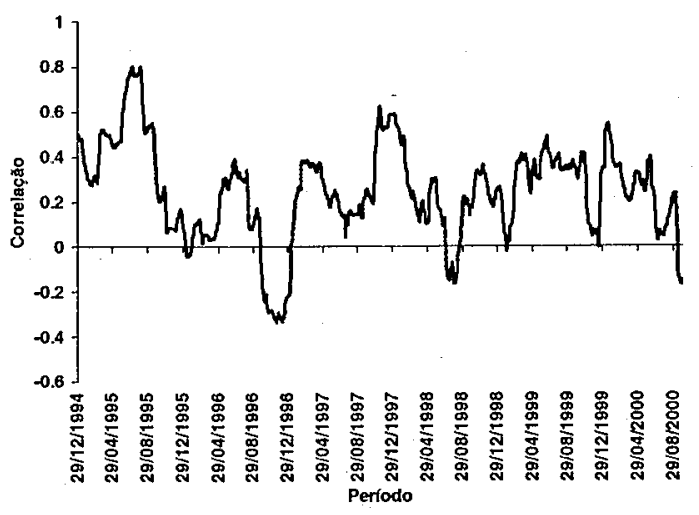

\section{Gráfico 13: hBBDC4 e hUBBR4}

${ }^{23}$ A correlação, aqui, foi calculada a partir de $\operatorname{Cov}(x, y) / \sigma_{x} \sigma_{y}$, onde, $\operatorname{Cov}(x, y)=\frac{1}{n} \sum_{j=1}^{n}\left(x_{j}-\mu_{x}\right)\left(y_{j}-\mu_{y}\right)$ 


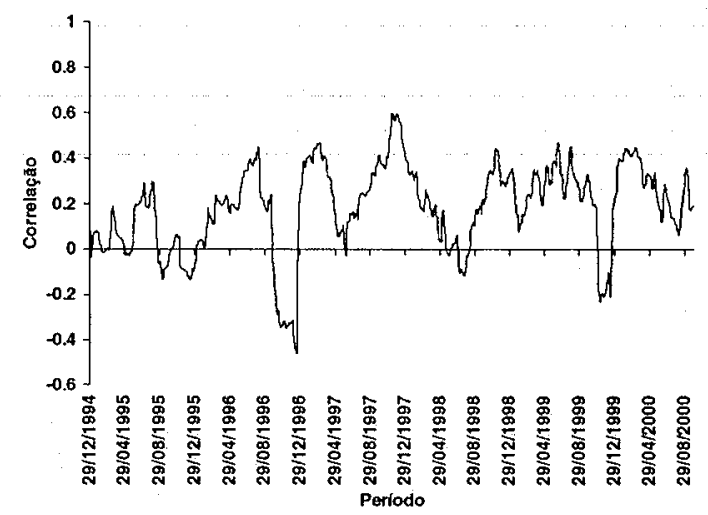

\section{Gráfico 14: hITAÚ4 e hUBBR4}

O primeiro vai de 02/08/1994 a 02/06/1997, ou seja, um período que se estende até a privatização do Banerj. O segundo momento considera os dados do período de 09/06/1997 a 02/10/ 2000 , ou seja, todos os retornos de ações após a privatização do Banerj. ${ }^{24}$ Os resultados para estas estimativas estão sintetizados na tabela 10.

Tabela 10: Correlações para os dois períodos

\begin{tabular}{ccc}
\hline \multicolumn{3}{c}{ Correlações } \\
\hline & Pós Priv. do Banerj & Pré Priv. do Banerj \\
\hline BBAS4XBBDC4 & 0,277 & 0,374 \\
\hline BBAS4XITAÚ4 & 0,229 & 0,387 \\
\hline BBAS4XUBBR4 & 0,128 & 0,208 \\
\hline BBDC4XITAÚ4 & 0,538 & 0,529 \\
\hline BBDC4XUBBR4 & 0,291 & 0,316 \\
\hline ITAÚ4XUBBR4 & 0,175 & 0,287 \\
\hline
\end{tabular}

Como pode ser visto, todas as correlações obtidas para ambos os períodos também foram significativas e com sinal positivo, sendo que as relativas ao período pós-privatização do Banerj são maiores do que as obtidas para o período anterior e também

${ }^{24}$ A amostra total abrange o período no qual ocorreram as seguintes privatizaçōes: Banerj (1997), Credireal (1997), Meridional (1997), Bemge (1998), Bandepe (1998), Baneb (1999) e Banestado (2000) 
para toda a amostra. É importante destacar que a única exceção é a queda na correlação na volatilidade de BBDC4 e ITAÚ4, que passou de 0,538 para 0,529 .

Desta forma, podemos concluir então que, com o início da privatização dos bancos estaduais, ocorreu um aumento da correlação existente entre a volatilidade do banco estatal e os outros bancos privados aqui considerados. Além disso, também foi possível constatar que ocorreu um aumento da correlação existente entre as ações das instituições privadas. Cabe salientar que a correlação entre BBDC4 e ITAÚ4 tem caído ao longo do tempo.

Este aumento na correlação pode estar sendo causado por uma modificação na política de mercado do banco estatal que, devido à grande concorrência, à queda da receita inflacionária, à pressão pública pela obtenção de resultados positivos e à existência de regras mais rígidas, sua gestão tenha sido forçada a atuar de forma mais próxima à dos bancos privados. Desta forma, esta atitude pode ter resultado em uma percepção de risco mais relacionada entre estas instituições por parte dos investidores.

Por fim, para verificar se a volatilidade entre o período pré e pós-privatização do Banerj é diferente, é estimado o modelo GARCH-GED univariado para ambos, onde os resultados das estatísticas $h_{t}$ para cada série se encontra na tabela 11 abaixo.

Tabela 11: Estatísticas para as volatilidades estimadas para os dois períodos

\begin{tabular}{cccccc}
\hline & \multicolumn{2}{c}{ Pré-priv. do Banerj } & \multicolumn{2}{c}{ Pós-priv. do Banerj } & \multirow{2}{*}{ Teste da Média } \\
\cline { 1 - 5 } & Média & Desv.pad & Média & Desv.pad. & \\
\hline hBBAS4 & 0,03025 & 0,0078 & 0,0333 & 0,0042 & $-9,22$ \\
\hline hBBDC4 & 0,0233 & 0,0103 & 0,0297 & 0,0065 & $-13,99$ \\
\hline hITAÚ4 & 0,0218 & 0,0047 & 0,0266 & 0,0036 & $-21,67$ \\
\hline hUBBR4 & 0,0281 & 0,0127 & 0,0318 & 0,0068 & $-6,80$ \\
\hline
\end{tabular}

Nota: O teste da média é unicaudal, e considera como hipótese Ho a igualdade entre as médias das volatilidades dos dois periodos. A hipótese H1 é de que a média do período pré-privatização é menor do que a média do período pós-privatização.

Como pode ser visto, todas as volatilidades médias no período pré-privatização são menores do que na amostra total (tabela 8), ao passo que a volatilidade média para o período pós- 
privatização é maior para todas as ações. Na comparação entre o período pré e pós-privatização, nota-se um aumento da volatilidade média. Por outro lado, o desvio-padrão da volatilidade caiu após a privatização do Banerj.

Assim, os resultados nos leva a crer que, com o início do programa de privatização de alguns bancos estatais, ocorreu uma modificação no processo de avaliação do Banco do Brasil, com os investidores precificando de forma mais criteriosa suas ações, que ganharam liquidez e tiveram um aumento significativo da sua volatilidade a partir de então.

Vale ressaltar que comportamento semelhante foi observado para as demais instituições financeiras aqui estudadas, que tiveram que se adaptar a uma nova realidade de mercado a partir da estabilização da economia com o Plano Real. Assim, pode-se afirmar que a privatização do Banerj significou um marco estrutural para o sistema financeiro brasileiro.

\section{Conclusões}

Os modelos da família GARCH fornecem informações importantes sobre as características de séries financeiras. A aplicação aqui feita para as ações do mercado bancário brasileiro revela que, além de todos os retornos possuírem médias próximas a zero, assimetria, curtose, distribuição não-normal e autocorrelação serial no quadrado dos retornos, também há a presença de aglomeração na volatilidade, persistência a choques e efeito assimetria.

Além disso, o banco estatal possui a menor média de retornos, o maior desvio-padrão além de ser a única ação a não ter influência da volatilidade na determinação da média dos retornos. Pelo teste de viés de sinal proposto por Engle (1993) para determinar se existe diferença entre choques de retornos positivos e negativos, nota-se também que o banco estatal não demonstra ter o efeito assimetria. Em relação à média dos retornos, a maior encontrada foi ITAÚ4, que também tem o menor desvio-padrão, ao passo que UBBR4 possui a maior persistência na volatilidade.

A partir do máximo do log da verossimilhança, selecionou-se o modelo univariado GARCH-GED como representativo da volatilidade de todas as ações. Os resultados mostraram que a 
volatilidade média aumentou para todas as ações do sistema bancário, entre o período pré e pós-privatização dos bancos estaduais.

Com o uso do modelo de correlação condicional constante proposto por Bolerslev (1990), também é verificado que as correlações entre as volatilidades aumentaram entre estes dois períodos, com destaque para a correlação entre o banco estatal e os privados. A existência desta maior correlação é dada pelas ações dos dois maiores bancos privados do país, o Bradesco e o Itaú.

Portanto, de acordo com os resultados aqui encontrados, pode-se dizer, que com o início da reestruturação do sistema financeiro nacional a partir do PROER e do PROES e, em especial, após a privatização do Banerj, o mercado financeiro passou a precificar o banco estatal de maneira mais próxima à que é feita para os bancos privados. Isto tem efeitos positivos não apenas para o próprio banco, mas também para todo o sistema financeiro, na medida em que reduziu o risco sistêmico.

\section{Referências bibliográficas}

ALMEIDA, N. M. C. G.; PEREIRA, P. L. V. (1999) - Mudança de Regime em Volatilidade. Os Modelos SWGARCH. Anais do XXI Encontro Brasileiro de Econometria, p. 39-58.

ALVES, D.; BUENO, R. L. S. (1998) - Co-persistence in Conditional Variances of Brazilian, Korean and American Stock Market Indexes, Anais do XX Encontro Brasileiro de Econometria, v.1, p. 31-44.

BAILLEE, R. T.; Bollerslev, T. (1990) - A Multivariate Generalized ARCH Approach to Modelling Risk Premia in Foward Foreign Exchange Rate Markets, Journal of International Money and Finance, v.9, p. 909-324.

BANCO CENTRAL DO BRASIL (2000) - Evoluçâo do Sistema Financeiro Nacionat. Bancos Brasileiros de Dezembro/1988 a Dezembro/2000 em www.bcb.gov.br.

BARCINSKI, A.; ALMEIDA, B. C. P.; GARCIA, M. G. P.; SILVEIRA, M. A. C. (1997) Estimação da volatilidade do retorno de açóes brasileiras. Um método alternativo à familia GARCH. Resenha BMEF, n. 116, p. 21-39.

BOLLERSLEV, T. (1986) - Generalized Autoregressive Conditional Heteroskedasticity, Journal of Econometrics, v. 31, p. 307-328.

BOLLERSLEV, T. (1987) - A conditionally Heteroskedastic Time Series Model for Speculative Prices and Rates of Return. The Review of Economics and Statistics, v. LXIX, n. 3, p. 542-47.

BOLLERSLEV, T. (1990) - Modelling the Coherence in Short-Run Nominal Exchange Rates: A Multivariate Generalized ARCH Model, The Review of Economics and Statistics, v. 72 , p. $498-505$. 
BOLLERSLEV, T; CHOU, R.Y; KRONER K.F. (1992) - ARCH Modeling in Finance; A Review of The Theory and Empirical Evidence, Journal of Econometrics, v. 52, p. 5-59. BOLLERSLEV, T., ENGLE, R.F., NELSON, D.B. (1994) - ARCH Models, in R.F. Engle $\mathcal{B}$ D.L. McFadden (eds) Handbook of Econometrics, v.4, North-Holland, Amsterdam, p.29593038.

BUSTAMANTE, M.; FERNANDES, M. (1995) - Um Procedimento para Análise da Persistência na Volatilidade. Anais do XVII Encontro Brasileiro de Econometria, p. 203-223.

CORREA, M.M.R.L.; PEREIRA,P.L.V. (1998) - Modelos não-lineares em Finanças: Previsibilidade em Mercados Financeiros e Aplicações a Gestão de Risco, Anais do XX Encontro Brasileiro de Econometria, v.1, p. 427-448.

DELGADO, SYLVIA (1994) - A Distribuição de Probabilidade dos Retornos das Açōes no Brasil, Revista Brasileira do Mercado de Capitais, v.19, n.48, p. 27-48.

DUARTE, J.A.M.; PINHEIRO, M.A.; HEIL, T.B.B. (1996) -Estimação da Volatilidade de Ativos e Índices Brasileiros. Resenha BMEF, n.111, p. 16-28.

ENGLE, R.F. (1982) - Autoregressive Conditional Heteroskedasticity With estimates of The Variance of The United Kingdom Inflation, Econometrica, v.50, p. 987-1007.

ENGLE,R.F.; KRONER,K.F. (1995) - Multivariate Simultaneous Generalized ARCH, Econometric Theory, v.11, p. 122-150.

ENGLE,R.F.; LILIEN,D.M.; ROBINS,R.P. (1987) - Estimating Time-Varying Risk Premia In The Term Structure, Econometrica, 55/2, p. 391-407.

ENGLE, R. F. ; NG, VICTOR K. (1993) - Measuring and Testing the Impact of News on Volatility, Journal of Finance, n.48/5, p. 1749-78.

GALVÃO, A.B.C.; PORTUGAL, M.S.; RIBEIRO, E.P. (2000) - Volatilidade e Causalidade: Evidências para o Mercado à Vista e Futuro de Índice de Ações no Brasil, Revista Brasileira de Economia, 54(1), p. 37-56.

GLOSTEN, L.R.; JAGANNATHAN, R.; RUNKLE, D. E. (1993) - On The Relation Between Expected Value and The Volatility of The Nominal Excess Return on Stocks, Journal of Finance, v. 48, p. 1779-1801.

GOURIÉROUX, C. (1996) - ARCH Models and Financial Applications, Springer, Berlin. HE, CHANGLI; TERÄSVIRTA, T. (2002) - An Extended Constant Conditional Correlation GARCH Model and Its Fourth-Moment Structure, SSE/EFI Working Paper Series in Economics and Finance, $N^{\circ} 509$.

GOLDFAJN, I.; HENNINGS, K.; MORI, H. (2003) - Brazil's Financial System: Resilience to Shocks, no Currency Substitution, but Struggling to Promote Growth, Banco Central do Brasil, Working Paper Series $N^{\circ} 75$.

HE, CHANGLI, TERÄSVIRTA, T. (1997) - Properties of the autocorrelation function of squared observations for second order GARCH process under two sets of parameters constraints, Working Paper Series in Economics and Finance, 169, Stockolm School of Economics.

HE, CHANGLI; TERÄSVIRTA, T. (1999) - Fourth moment structure of the GARCH(p,q) process, Econometric Theory, v. 15, n.6, p.824-46.

HE, CHANGLI; TERÄSVIRTA, T. (2002a) - An Application of the Analogy between Vector $\mathrm{ARCH}$ and Vector Randon Coefficient Autoregressive Models, SSE/EFI Working Paper Series in Economics and Finance, $N^{\circ} 516$. 
HE, CHANGLI, TERÄSVIRTA, T., Malmsten, H. (2002) - Moment structure of a family of first-order exponential GARCH models, Econometric Theory, v.18, n.4, p. 868.85.

HERENCIA, M.E.Z; HOTTA, L.K.; PEREIRA, P.L. (1998) - Filtragem e Previsão com Modelos de Volatilidade: Volatilidade Estocástica Versus GARCH. Revista de Economia, V.52, n.2, p.241-278.

ISSLER, J.V. (1999) - Estimating and Forecasting the Volatility of Brazilian Finance Series Using ARCH Models, Revista de Econometria, v.19, n.1, p. 5-56.

KIM, D.; KON, S.J. (1994) - Alternative Models for The Conditional Heteroscedasticity of Stock Returns, Journal of Business, v. 67, N. 4, p. 563-598.

KRONER, K., F.; SULTAN, J. (1993) - Time-Varying Distribution and Dynamic Hedging with Foreign Currency Options, Journal of Financial and Quantitative Analysis, v.28(4), p. 535-551.

LONGIN, F.; SOLNIK, B. (1995) - Is the Correlation in International Equity Returns Constant: 1960-1990?, Journal of International Money and Finance, v. 14, p. 3-26.

Maia, G.V.S. (2003) - Reestruturação Bancária no Brasil: o Caso do PROER, Banco Central do Brasil, Nota Técnica No 38.

MORAES Jr., A.C.; MORAIS, I.A.C. (2002) - Práticas Diferenciadas de Governança Corporativa: do problema da seleção adversa no mercado acionário aos impactos sobre a volatilidade das ações, In: Congresso ABAMEC, 16, Porto Alegre - RS, Abril 2002, Anais do XVI Congresso ABAMEC.

MORAIS, I.A.C.; PORTUGAL, M.S. (1999) - Modelagem e Previsão de Volatilidade Determinística e Estocástica para a Série do Ibovespa, Estudos Econômicos, v.29, n.3, p.303-341.

NELSON, D.B. (1991) - Conditional Heteroskedasticity in Asset Returns: A New Approach, Econometrica, v.59, p.347-70.

RACINE, M.D.; ACKERT,L.F. (1998) - Time-Varying Volatility in Canadian and U.S. Stock Index Futures Markets: A Multivariate Analysis, Working Paper, 98-14, Federal Reserve Bank of Atlanta.

TERÄSVIRTA, T' (1996) - Two stylized facts and the GARCH(1,1) model, Working Paper Series in Economics and Finance, 96, Stockholm School of Economics.

ZIEGELMANN, F.A.; PEREIRA, P. V. (1997) - Modelos de Volatilidade Estocástica com Deformação Temporal: Um Estudo Empírico para o Índice Bovespa. Pesquisa e Planejamento Econômico, v. 27, N.2, p. 353-376. 